\title{
SISTEM INFORMASI RELAWAN SAKSI TIM SUKSES PASLON 03 (ZAIRIN- SARWONO) PADA PILWALI 2020
}

\section{INFORMATION SYSTEM OF VOLUNTEER WITNESS TEAM SUCCESS TEAM PASLON 03 (ZAIRIN-SARWONO) AT THE 2020 PILWALI}

\author{
Muhamad Duki ${ }^{1}$ Fahrullah $^{2 *}$, Riyayatsyah ${ }^{3}$ \\ ${ }_{1,2,3}$ Universitas Mulia, Jalan Pahlawan 2A, Samarinda \\ *E-mail: fahrullah@universitasmulia.ac.id
}

\begin{abstract}
ABSTRAK
Tujuan dilaksanakannya penelitian ini untuk membuat aplikasi sistem informasi relawan saksi tim sukses pasangan calon 03 (Zairin-Sarwono) pada pilwali 2020 sehingga masalah lapangan yakni pendataan, penyaringan data fiktif, efisiensi waktu kerja, kemudahan mengakses laporan hasil kerja untuk menghemat pengeluaran, meminimalisir fraud (kecolongan, penggelembungan, dan rekayasa data), dan melakukan sampling calon pemilih mendapatkan solusi tepat. Metode penelitian yang digunakan adalah observasi, wawancara, dan kajian pustaka. Metode rancang bangun aplikasinya menggunakan Rapid Application Development (RAD), ERD, DFD, FOD, HiPo dan CD. Sedangkan pilihan teknologi berupa website dan Android yang dibangun menggunakan framework Laravel, framework Quasar, dan database MySQL. Setelah diujikan di lapangan, penggunaan aplikasi pendataan ini terbukti mampu mengurangi tingkat kerumitan, mengurangi pelaporan data yang sering overlap (tumpang tindih), mengurangi kecolongan data oleh pihak-pihak tidak bertanggung jawab, meminimalisir fraud (kecolongan, penggelembungan, dan rekayasa data) oleh oknum-oknum tidak bertanggungjawab. Dengan aplikasi ini, kesulitan dan hambatan saat berkolaborasi di pilwali Samarinda 2020 menjadi berkurang misalkan pelaporan, dan sebagainya sesuai fitur yang ada. aplikasi tersebut bisa untuk membantu tim sukses melakukan sampling calon pemilih sebagai upaya pemetaan keberhasilan kampanya lapangan. Fitur penginputan data master petugas, data master kordinator lapangan, data klasifikasi relawan, data klasifikasi penghubung, data klasifikasi saksi TPS, data klasifikasi saksi gugur, data klasifikasi temuan saksi TPS, dan data klasifikasi calon pemilih mampu meningkatkan kinerja tim lebih baik.
\end{abstract}

Kata Kunci: sistem informasi, pemilihan kepala daerah, pendataan relawan saksi.

\begin{abstract}
The purpose of this research is to make an information system application for witnesses of the successful team of candidate pairs 03 (Zairin-Sarwono) in the regional elections in Samarinda 2020, that problems are data collection, fictitious data, work time efficiency, ease of accessing results reports to save expenses, minimize fraud (cheating, ballooning, and data engineering), and sampling prospective voters to get the right solution. The research method used is observation, interviews, and literature review. The application design method uses Rapid Application Development (RAD), ERD, DFD, FOD, HiPo and CD. While the technology choices are websites and Android which are built using the Laravel framework, the Quasar framework, and the MySQL database.After being tested in, the use of this data collection application has been proven to be able to reduce the level of complexity, reduce data reporting that often overlaps, reduces data being missed by irresponsible parties, minimizes fraud, bubbles, and data engineering by irresponsible persons. With this application, the difficulties and obstacles when collaborating in the 2020 Samarinda election are reduced, for example reporting, and so on according to existing features. This application can be used to help the team successfully conduct a sampling of prospective voters as an effort to succeed in their field campaign. The features of inputting officer master data, coordinator master data, field data classification, liaison data classification, TPS witness data classification, fall data classification, TPS findings classification data, and classification data classification were able to improve team performance better.
\end{abstract}

Keywords: information system, regional head election, data collection of witness volunteers 


\section{PENDAHULUAN}

Setiap 5 tahun sekali ada kegiatan pemilihan walikota dan wakil walikota (pilwali) di Samarinda yang diikuti oleh banyak calon. Kegiatan tersebut melibatkan masyarakat untuk menyalurkan hal pilih kepada pasangan calon masing-masing. Para kontestan akan saling berusaha mendapatkan paling banyak dukungan suara agar bisa menang. Untuk itu pendataan masyarakat, relawan, saksi sangat dibutuhkan agar aksi tim sukses tepat sasaran.

Terjadi perubahan Undang-Undang tentang pilkada dari Nomor 32 Tahun 2004 yang berbunyi peserta pemelihan kepala daerah (pilkada) adalah pasangan calon (paslon) yang diusulkan oleh partai politik atau gabungan partai politik, menjadi Undang-Undang Nomor 12 Tahun 2008 yang menyatakan bahwa peserta pilkada juga dapat berasal dari pasangan calon perseorangan yang didukung oleh sejumlah orang. Undang-undang Nomor 12 Tahun 2008 menindaklanjuti keputusan Mahkamah Konstitusi (MK) yang membatalkan beberapa pasal menyangkut peserta Pilkada dalam Undang-Undang Nomor 32 Tahun 2004 (kemenkeu, 2004).

Pasangan Zairin-Sarwono dengan urut nomor 3 adalah pasangan independen yang lolos verifikasi. KPU Samarinda menetapkan pasangan ini telah memenuhi syarat dukungan suara sebanyak 51.652 melebihi syarat minimal 43.977 suara berdasarkan hasil siding pleno terbuka rekapitulasi dukungan. Dengan hasil demikian pasangan tersebut telah memenuhi syarat sebagai calon dan bisa mendaftarkan diri saat pendaftaran pilkada Samarinda 2020 (samarinda.kompas, 2020).

Agar dapat memenangkan kontestasi politik pada pilwali 2020 di Samarinda ini, salah satu elemen penting yakni peran relawan saksi karena punya peran krusial pada saat hari pencoblosan di Tempat Pemungutan Suara (TPS), sehingga selama proses pilwali, tim sukses harus teliti dalam mendata relawan saksi. Karena dalam dunia politik ada upaya saling memata-matai, saling susup menyusupkan saksi atau relawan ke kubu musuh untuk mendapatkan informasi juga sekaligus membiaskan sebuah rencana politik yang ada. Sehingga transaparansi dan akuntabilitas dari sebuah data relawan saksi perlu difilter sampai pada tahap final. Artinya kita tahu bahwa saksi atau relawan tersebut benar-benar murni mendukung paslon dan bekerja secara profesional. Selain menyangkut keamanan, kredibilitas data relawan saksi juga menyangkut anggaran operasional yang tidak sedikit.
Tugas dan pekerjaan saksi di Tempat Pemungutan Suara (TPS) tidaklah mudah. Harus dilakukan oleh orang-orang yang berpengalaman dan kritis melihat situasi pencoblosan. Mampu melihat adanya pelanggaran-pelanggaran saat itu. Para saksi harus tahu betul situasi dan kondisi daerah serta TPS yang akan di pantau, serta memahami secara detail dan rinci aturan-aturan main yang ada di TPS-TPS. Sebagai contoh, apakah Daftar Pemilih Tetap (DPT) terpampang di TPS, apakah kotak suara tersegel, apakah masih ada Alat Peraga Kampanye (APK) lawan yang dapat mempengaruhi pemilih dalam radius tertentu, apakah masih ada warga yang belum mendapat formulir C6 (surat pemberitahuan lokasi memilih/ TPS). Harus tahu betul tugastugas Panitia Pemungutan Suara (PPS) dan Kelompok Penyelenggara Pemungutan Suara (KPPS), khususnya Ketua KPPS dan PPS, juga harus mengetahui tujuh orang petugas KPPS apa saja tugasnya.

Pekerjaan terberat bagi tim sukses selain melakukan kampanye salah satunya adalah pengelolaan data relawan saksi ZairinSarwono paslon 03. Kendala yang terjadi di lapangan selama melaksanakan tugas ini antara lain: siklus data yang rumit, mekanisme kerja yang ruwet (berbenturan), pelaporan data yang sering overlap (tumpang tindih), sampai kecolongan data oleh pihak-pihak tidak bertanggung jawab.

Dengan memanfaatkan perkembangan teknologi informasi dalam kegiatan berpolitik khususnya usaha kemenangan Zairin-Sarwono pada pilkada 2020 Samarinda, maka perancangan aplikasi relawan saksi TPS diperlukan oleh tim sukses Zairin-Sarwono pada pilkada 2020. Tujuan dilaksanakannya penelitian ini menghasilkan sistem informasi yang relevan dengan masalah lapangan yakni pendataan, penyaringan data fiktif, efisiensi waktu kerja, kemudahan mengakses laporan hasil kerja untuk menghemat pengeluaran, meminimalisir fraud dan sampling calon pemilih.

\section{METODOLOGI}

Pelaksanaan penelitian ini dilakukan di posko utama pemenangan Zairin-Sarwono Jalan Bhayangkara, Bugis, Kec. Samarinda Ulu, Kota Samarinda, Kalimantan Timur 75121, Indonesia. Pelaksanaan penelitian dilakukan mulai dari bulan Oktober 2020 sampai dengan 30 Desember 2020.

Metode pengumpulan data dilakukan studi literatur dari berbagai buku serta 
referensi mengenai pembuatan aplikasi. Selain itu juga dilakukan kegiatan wawancara dilakukan untuk memperoleh informasi penting dari ketua tim sukses, tim koordinator, tim jaringan sosial, tim IT, dan tim pendata. Dalam penelitian ini wawancara dilakukan untuk memperoleh informasi mengenai tugas pokok tim, alur kerja serta kesulitan yang dialami serta kriteria sistem yang akan dibuat.

Pengembangan sistem informasi menggunakan metode Rapid Application Development (RAD).

\section{HASIL DAN PEMBAHASAN \\ Evaluasi Proses Berjalan}

Pada FoD tergambar pihak-pihak yang bekerja yaitu kordinator, jaringan sosial, pendata, staf IT, dan ketua.

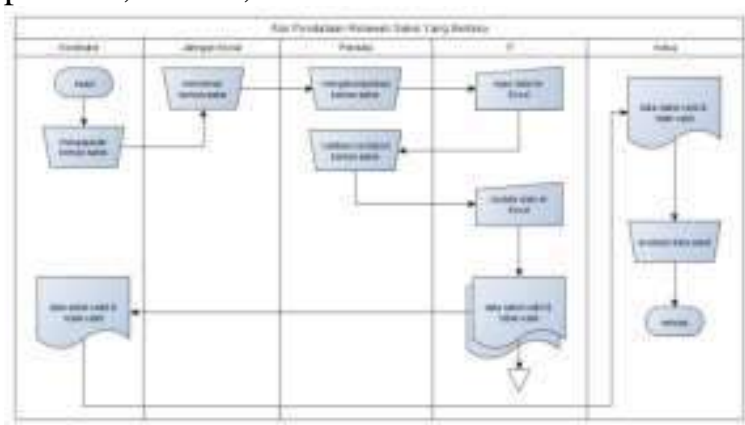

Gambar 1. FoD Berjalan

Proses bermula dari kordinator wilayah yang mengumpulkan berkas relawan saksi kepada tim jaringan sosial. Selanjutnya ditata berkasnya oleh tim pendata kemudian diinput ke dalam Excel oleh tim staf IT. Data tersimpan di validasi dengan memberikan parameter khusus. Tim pendata bertugas menelpon data relawan saksi apakah benar adanya telah mengajukan diri. Staf IT akan meng-update data tersebut sesuai validasi.

\section{Flow of Document Usulan}

Dalam FoD usulan terdapat perubahan mekanisme. Hal ini karena pemanfaatan aplikasi sehingga strandar operasional prosedur (SOP) menyesuaikan.

Pada gambar 2, perubahan terjadi pada bagian pendata dan staf IT. Hasil klasifikasi secara otomatis akan ditransformasi oleh aplikasi menjadi laporan grafik yang diteruskan kembali ke kordinator lapangan sebagai pencapaian kerja. Ketua tim sukses pemenangan dan stakeholder lainnya bisa mengakses aplikasi untuk melakukan pengawasan, pemantauan, dan evaluasi program kerja.

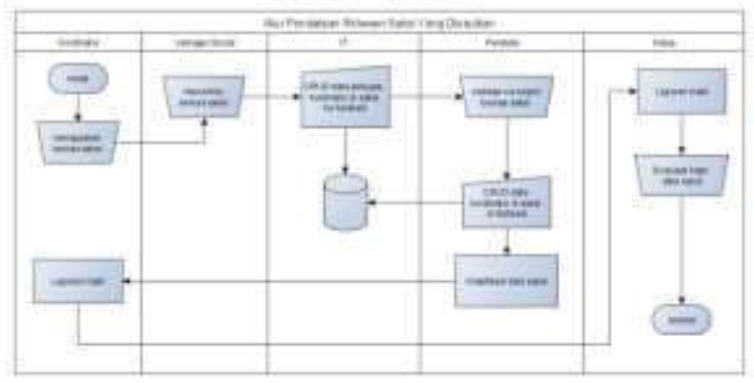

Gambar 2. FoD Diusulkan

\section{Context Diagram}

Context Diagram adalah mengenai apa yang dikerjakan perangkat lunak, siapa yang menggunakan serta apa yang menjadi input dan output-nya.

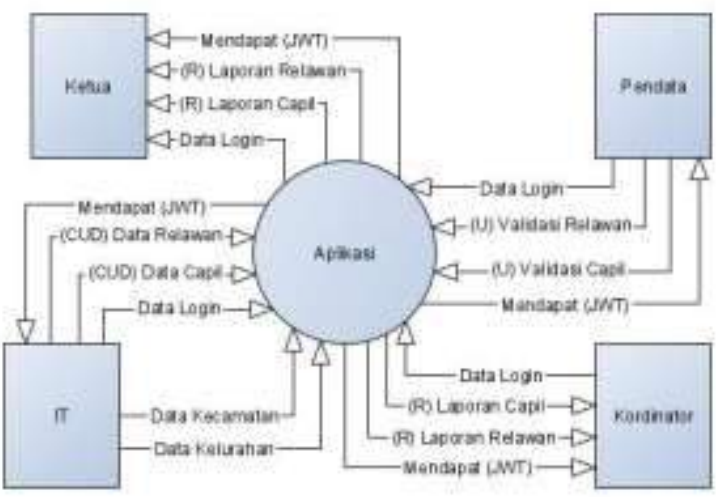

Gambar 3. Context Diagram

\section{Data Flow Diagram (DFD)}

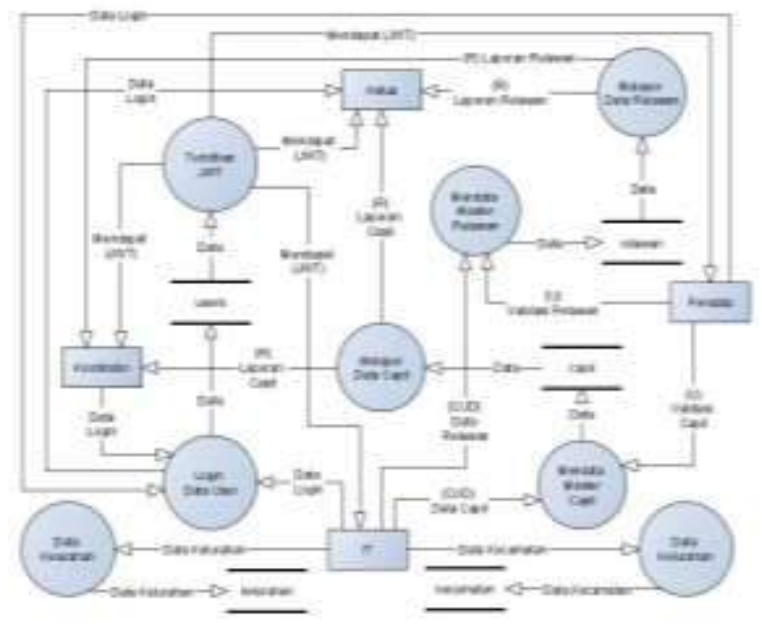

Gambar 4. DFD 


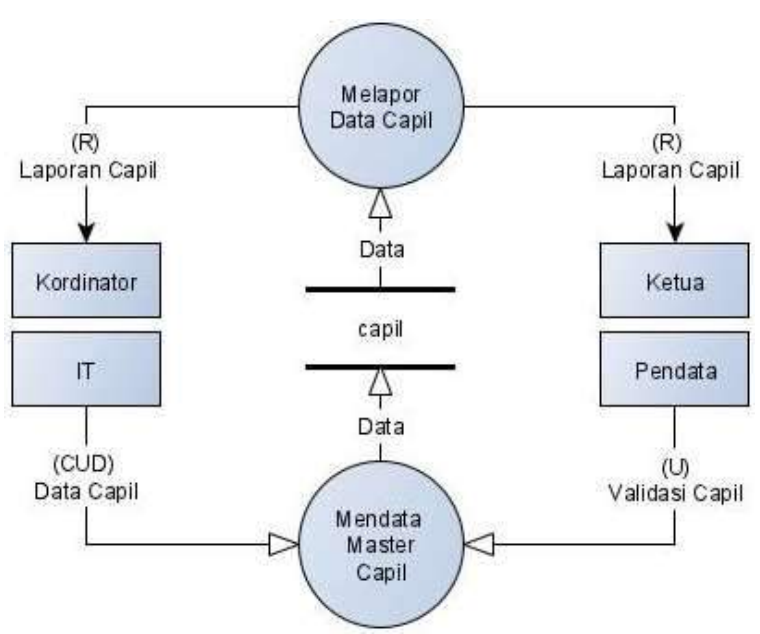

Gambar 5. DFD Level 1 Data Capil

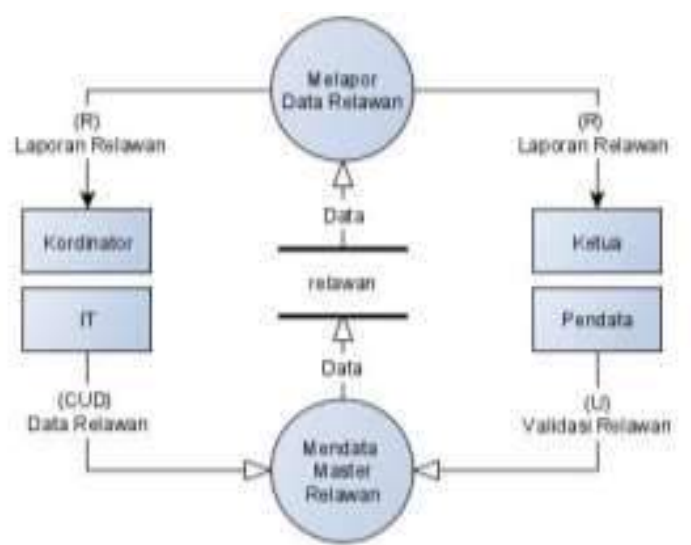

Gambar 6. DFD Level 1 Data Relawan

Data Flow Diagram biasa digunakan untuk menjelaskan proses-proses pada sistem informasi mencakup pula aliran informasi yang keluar dan masuk ke sistem. Data Flow Diagram pada aplikasi pendataan saksi relawan ini terbilang cukup sederhana, hal ini menganut prinsip minimal input maksimal output agar proses edukasi pada petugas singkat, artinya aplikasi harus semudah mungkin.

\section{Entity Relationship Diagram}

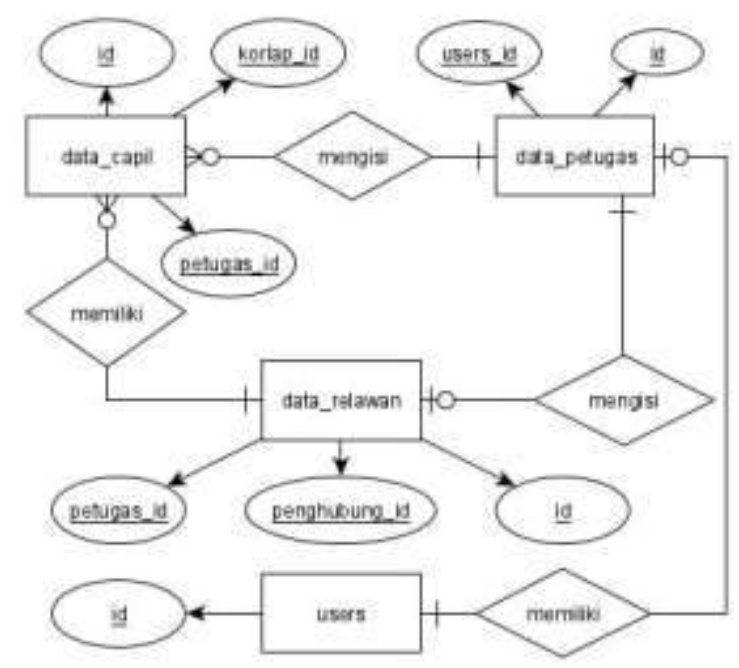

Gambar 7: ERD Master Tabel

Master table merupakan data yang diinput oleh petugas sebagai data inti. Kemudian divalidasi sesuai klasifikasi masingmasing untuk dilakukan view terhadap data master ini. Data master hanya bisa diisi dan dimodifikasi oleh user yang memiliki role (create, update). Selama prosesnya beberapa atribut penting akan menyesuaikan fakta lapangan saat proses verifikasi oleh pendata.

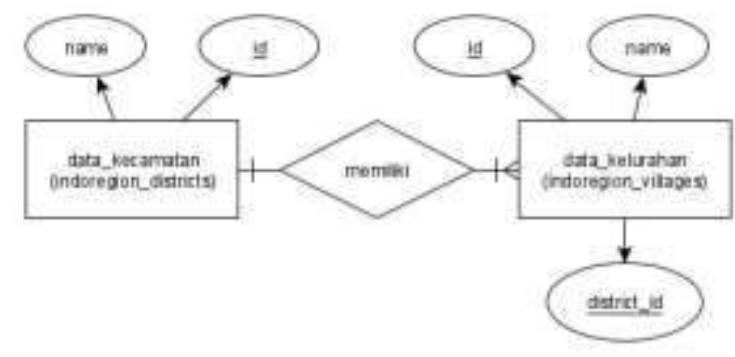

Gambar 8. ERD Kecamatan \& Kelurahan

Tabel kecamatan dan kelurahan digunakan pada UI/UX drop-down untuk mempercepat proses pengisian data agar seragam, daripada diketik manual. Alasan tidak menggunakan ini sebagai relasi utama karena data kecamatan dan kelurahan tidak berubah, jumlahnya terlalu banyak untuk direlasi secara quey.

\section{HIPO}

Adapun HIPO yang dibuat pada rancang bangun aplikasi sebagai berikut:

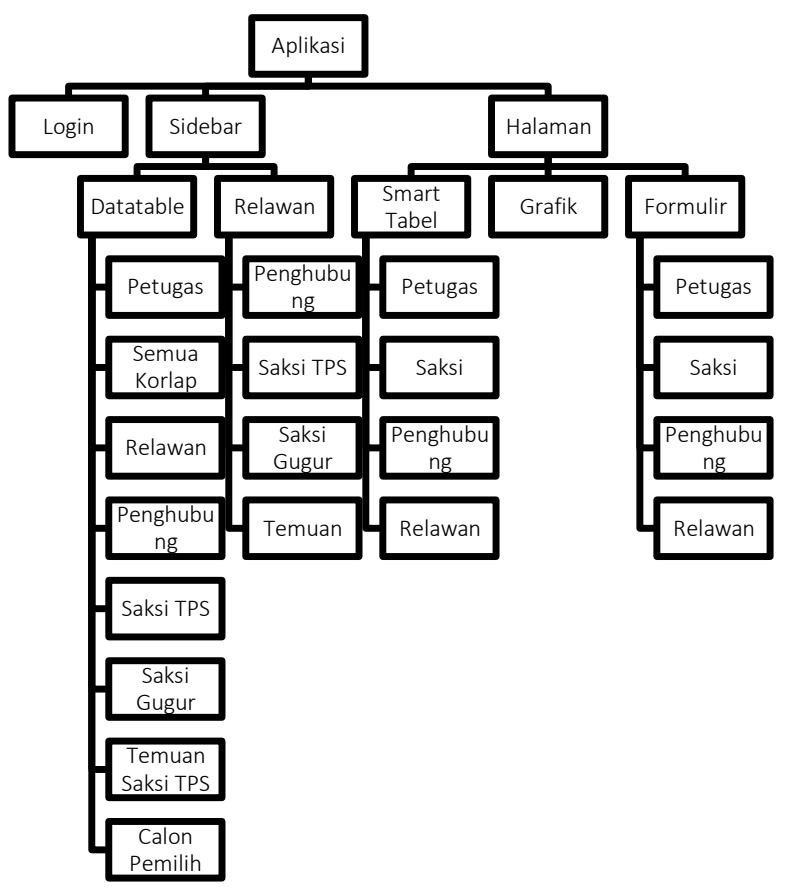

Gambar 9. HIPO 


\section{Mockup Aplikasi}

Prototype aplikasi pendataan relawan saksi paslon 03 pada pilwali samarinda 2020.

1. Tampilan Halaman Login

Tampilan pada Login pada sistem ini akan muncul pertama kali disetiap program dibuka, dimana username dan password harus terdaftar terlebih dahulu, kecuali user telah login sebelumnya dan status token masih aktif, maka system akan otomatis mengalihkan ke halaman dashboard.
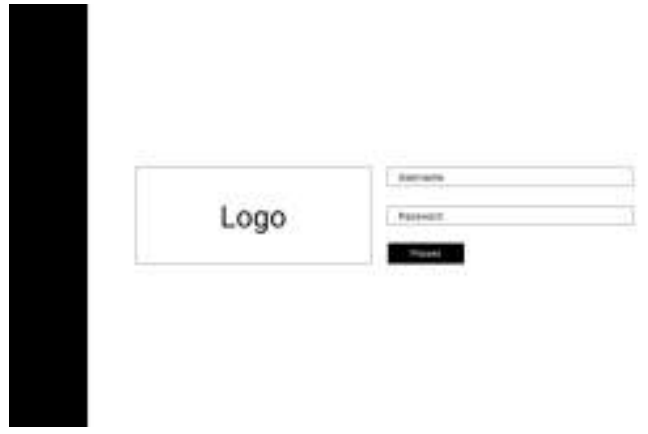

Gambar 10. Halaman Login

\section{Tampilan Halaman Laporan}

Tampilan grafik adalah bentuk klasifikasi data sekaligus berfungsi sebagai pelaporan untuk pihak-pihak terkait. Grafik dimulai dari data tingkat kecamatan, ke tingkat kelurah, ke tingkat RT, dan terakhir adalah smart table dari data tingkat RT. Jenis grafik yang digunakan adalah horizontal bar yang disusun secara vertical. Terdapat juga atributatribut berupa teks dan angkat sebagai informasi. Berikut ini adalah layout yang akan digunakan.

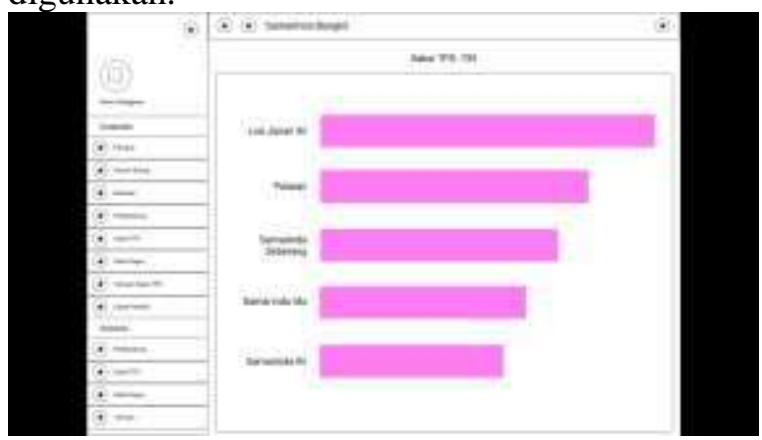

Gambar 11. Layout Grafik Laporan

\section{Tampilan Halaman Formulir}

Adapaun tampilan formulir untuk digunakan memasukkan data ke dalam database. Jenis formulir ada 3 yakni formulir capil, formulir korlap, formulir petugas. Masing-masing formulir memiliki atribut khusus dan atribut umum.

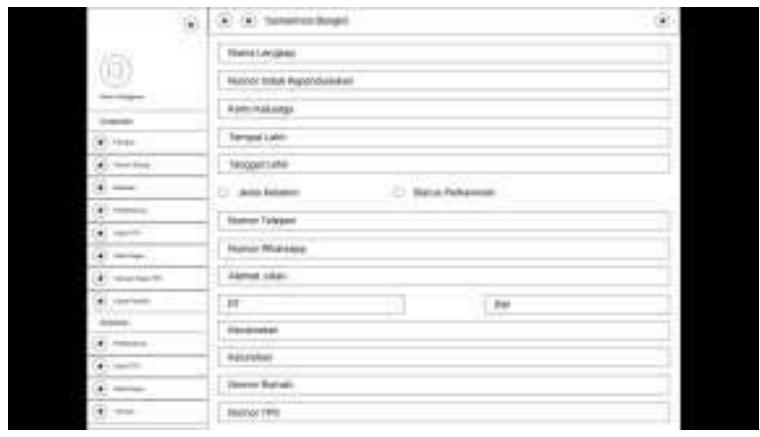

Gambar 12. Layout Formulir

\section{Tampilan Halaman Smart Tabel}

Adapun layout untuk menampilkan kumpulan data yang sudah tersimpan menggunakan smart table ini.

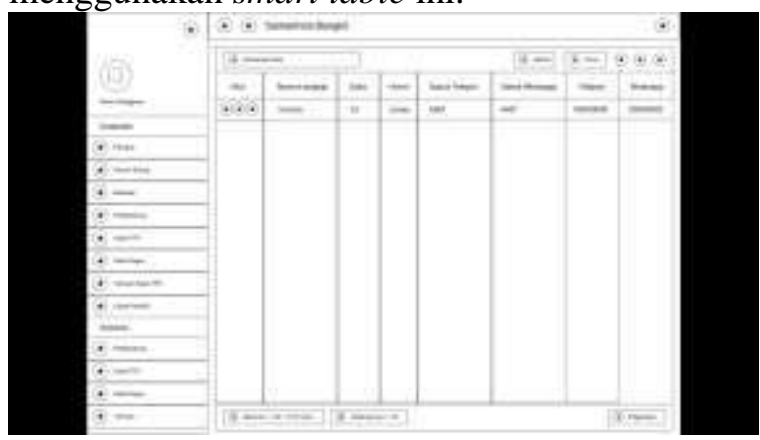

Gambar 13. Prototype Layout Smart Tabel

Fitur smart table ini memiliki kemampuan untuk mensortir data, memilih kolom-kolom, mengubah data secara parsial tidak melalui formulir, memiliki akses untuk terkoneksi dengan telepon, terdapat pula fitur pagination yang berfungsi mengurangi beban request ke database, dan ada pula fitur pencarian data. Smart table juga menjadi jembatan referensi data apabila ingin mengakses formulir pada data tertentu untuk kemudian di-update atau di-delete.

\section{Pengujian Sistem (Blackbox Testing)}

Metode pengujian yang akan digunakan pada sistem ini adalah Blackbox Testing yang berfokus pada fungsional aplikasi, apakah aplikasi yang dibuat sudah berfungsi dengan benar dan mencari kesalahan pada suatu fungsi sistem. Pengujian dilakukan dengan membuat skenario beberapa pengujian fungsi-fungsi terhadap aplikasi, tabel 2 berikut merupakan skenario yang digunakan: 


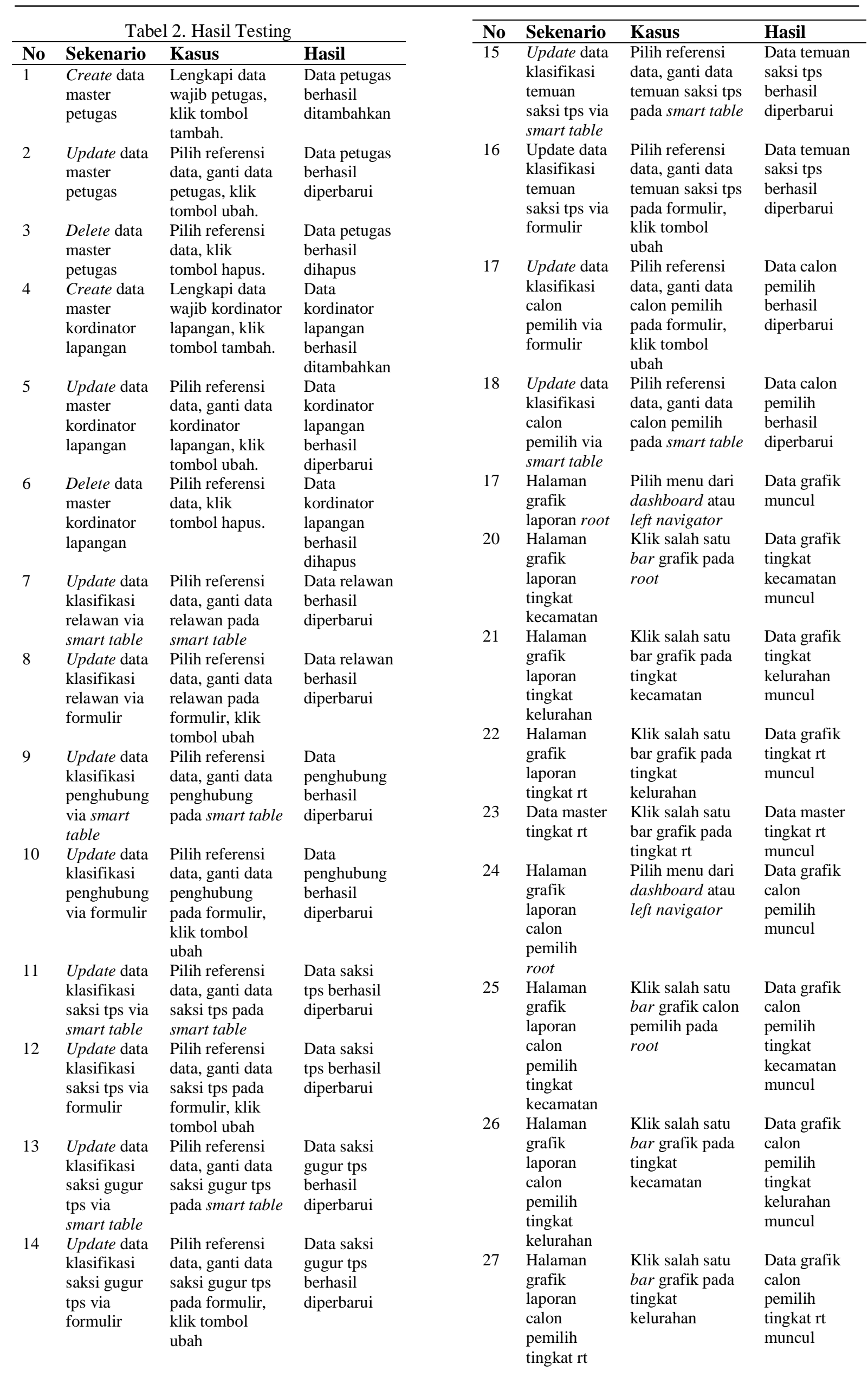




\begin{tabular}{llll}
\hline No & Sekenario & Kasus & Hasil \\
\hline 28 & $\begin{array}{l}\text { Data master } \\
\text { calon } \\
\text { pemilih } \\
\text { tingkat } \mathrm{rt}\end{array}$ & $\begin{array}{l}\text { Klik salah satu } \\
\text { bar grafik pada } \\
\text { calon pemilih } \\
\text { tingkat } \mathrm{rt}\end{array}$ & $\begin{array}{l}\text { Data master } \\
\text { calon } \\
\text { pemilih } \\
\text { tingkat } \mathrm{rt} \\
\text { muncul }\end{array}$ \\
& Login user & $\begin{array}{l}\text { Lengkapi } \\
\text { username dan } \\
\text { password, klik } \\
\text { tombol login }\end{array}$ & $\begin{array}{l}\text { User } \\
\text { dialihkan ke } \\
\text { halaman } \\
\text { dashboard } \\
\end{array}$ \\
& & $\begin{array}{l}\text { setelah } \\
\text { masuk }\end{array}$ \\
& & & \\
& & & \\
& & &
\end{tabular}

\section{Pengujian Sistem (Alpha Testing)}

Pada fase ini penulis selaku pengembang aplikasi melakukan kolaborasi dengan tim sukses khususnya bagian pendata, dan staf IT untuk memastikan bahwa fitur tertentu tidak cacat coding. Misalnya fitur login, dicoba oleh staf IT apakah masih bug, error, atau tidak setelah selasai dikoding. Jika menurut alpha tester sudah bekerja sebagaimana mestinya, akan di-merge dengan codebase utama. Ritme akan diulang sampai semua fitur selesai.

\section{Pengujian Sistem (Beta Testing)}

Pada fase ini semua fitur utama yang menjadi pondasi aplikasi sudah selesai dikerjakan. Penulis kemudian melakukan proses upload ke server untuk memastikan aplikasi bekerja di environment production. Kemudian penulis akan mempersilahkan seluruh stakeholder yang terkait untuk mencoba aplikasi sekaligus memberikan masukanmasukan fitur.

\section{Struktur Data}

Untuk menjelaskan Entity Relationship Diagram maka dibutuhkan struktur data. Penggunaan table view tidak perlu struktur data karena otomatis homogen berfungsi sebagai cache penyimpanan data sementara untuk mempercepat request. Terdapat 6 tabel yang dibuat struktur data yakni: tabel relawan, tabel petugas, tabel kecamatan, tabel capil, table user, dan tabel kelurahan.

\section{Deployment}

\section{Hosting Webserver}

Berikut ini adalah spesifikasi layanan hosting yang penulis gunakan untuk online aplikasi. Salah satu kelebihan dari PHP antara lain didukung banyak layanan hosting. 
setiap platform baik iOS atau Android memiliki engine wrapper (iOS WKWebViewEngine dan Android WebViews). Penulis menggunakan perintah "\$ quasar build -mode cordova target android".

Penggunaan teknologi Cordova untuk membuat aplikasi Android/iOS sangat bersinergi dengan teknologi SPA dari Vue.js dan Quasar. Performa yang dihasilkan dengan teknologi ini cukup kompetitif, tidak jauh berbeda dengan performa aplikasi mobile native. Juga karena Quasarframework sudah dilengkapi setingan dan dokumentasi yang bagus untuk teknologi mobile iOS/Android.

\section{Hasil Aplikasi (SPA / Android)}

1. Halaman Login

Berikut ini adalah tampilan halaman login :

\section{SAMARINDA
BANGKIT}

Gambar 15. Tampilan Halaman Login

2. Halaman Dashboard

Berikut ini tampilan halaman dashboard segmen ringkasan umum.

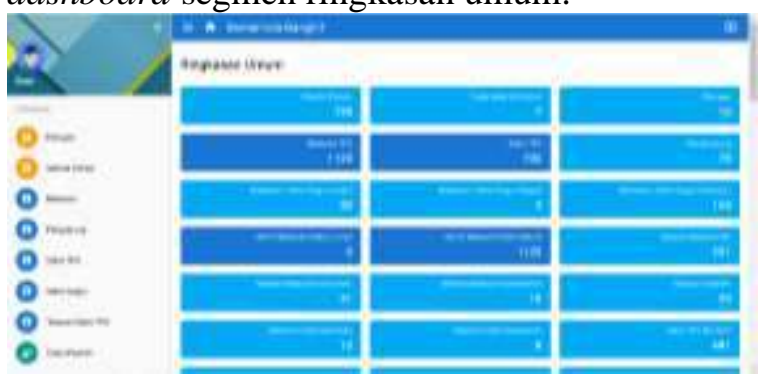

Gambar 14. Tampilan Halaman Dashboard

Berikut ini adalah tampilan halaman formulir, yang kosong untuk diisi data, berisi atribut umum untuk dilengkapi. Adapun formulir untuk data saksi, data kordinator, data penghubung, data calon pemilih, data staf, dan data otentikasi.

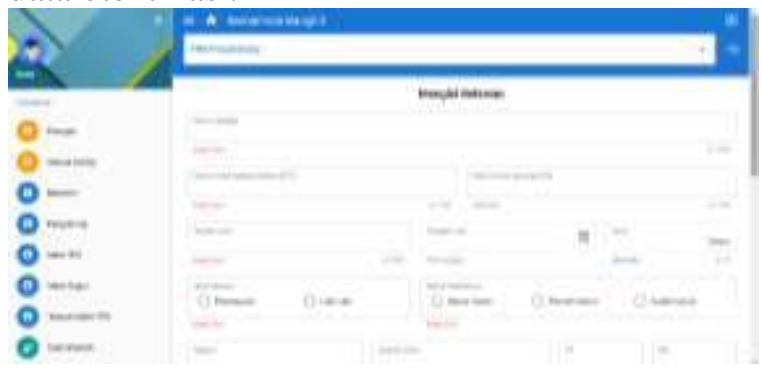

Gambar 16. Tampilan Halaman Formulir
Kemudian lagi adalah tampilan halaman table master saksi, table master kordinator, table master penghubung, table master calon pemilih, dan table master staf.

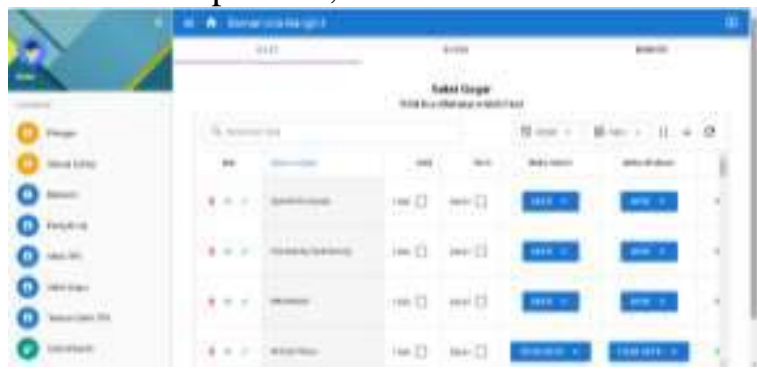

Gambar 17. Tampilan Halaman Table Master

Berikut ini adalah tampilan halaman laporan berbentuk grafik. Adapun klasifikasi laporan untuk data saksi, data kordinator, data penghubung, data calon pemilih, data staf, dan data otentikasi.

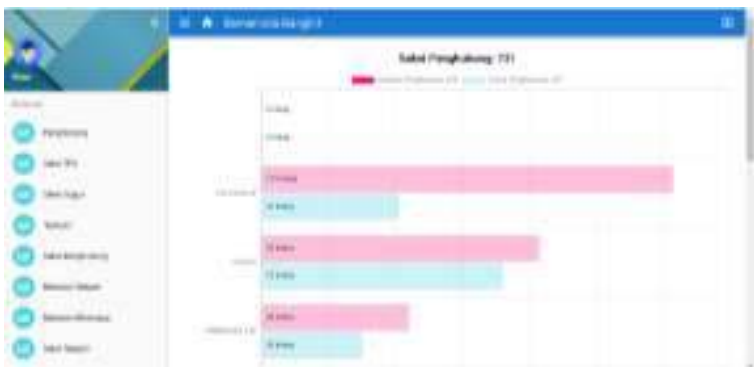

Gambar 18. Tampilan Halaman Laporan Grafik

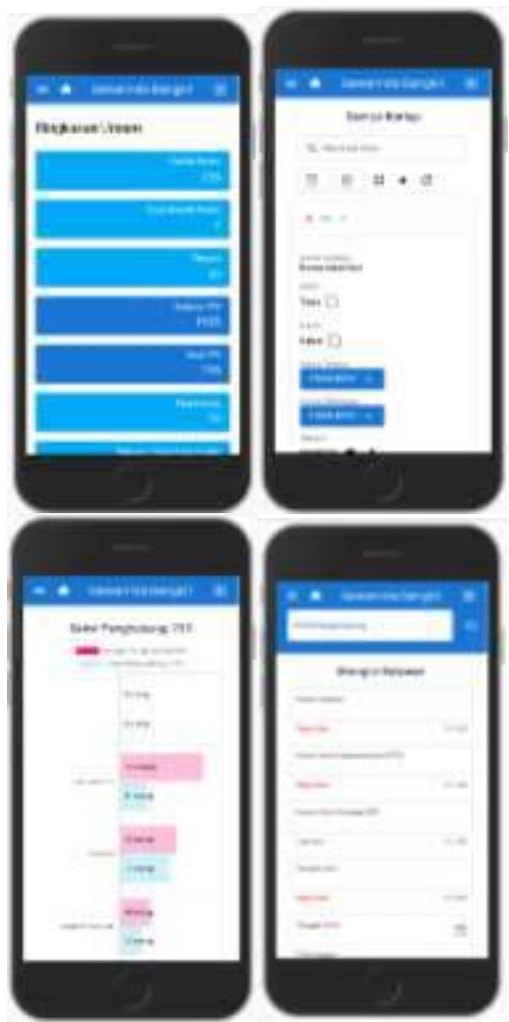




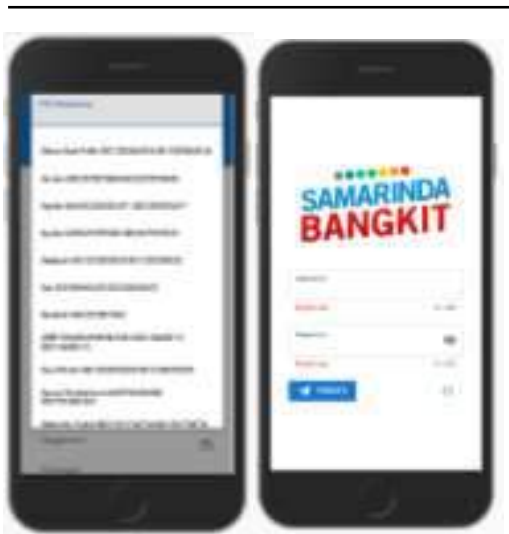

Gambar 19. Tampilan Android

\section{Implementasi}

Ini masuk fase penerapan sekaligus pengujian bagi sistem baru serta merupakan tahap dimana aplikasi siap dioperasikan pada keadaan yang sebenarnya, efektifitas sistem baru akan diketahui secara pasti, juga untuk semua kelebihan dan kekurangan sistem aplikasi.

Fokus implementasi yakni penerapan kepada user sekaligus pengujian bagi sistem pendataan ini apakah fitur-fitur sudah berjalan sesuai harapan. Mengingat platform yang menjadi tujuan adalah website dan Android, maka aplikasi harus bisa berjalan di platform tersebut. Proses yang harus dilalui setelah development yaitu production deployment, dimana pengembang akan meng-online-kan aplikasi, dan build aplikasi untuk versi Android. Perlu diketahui bahwa pada proses upload perlu server (hosting) berbeda-beda menyesuaikan penyedia layanan.

\section{Incremental Development Review}

Berdasarkan hasil implementasi yang telah dilakukan, tentu masih ada beberapa hal yang masih bisa dioptimalkan lagi, misalnya ada fitur push notification sehingga para pengguna lainnya khususnya stakeholder bisa mendapatkan notifikasi pembaruan data oleh staf IT atau pendata.

Jika pun ada bug atau glitch selama penggunaan, peneliti berusaha memperbaiki tepat waktu agar aplikasi bekerja lagi. Peneliti juga memberikan edukasi kepada pihak-pihak yang bersangkutan bagaimana mengoperasionalkan aplikasi pendataan ini agar maksimal.

Pengembangan versi selanjutnya dapat menambahkan fitur-fitur seperti survey, mengimplementasikan Supervised Machine Learning dengan algoritma-algoritma yang cocok, menjadikan basis data yang ada sebagai data training, juga implementasi Data Mining bisa dengan mengubah laporan-laporan menjadi Data Mart. Tidak menutup kemungkinan juga untuk menjadi Big Data Master pilkada, pilwali, dan pilpres. Aplikasi ini berpotensi untuk transformasi menjadi sistem pembuat keputusan (SPK) di masa yang akan datang.

\section{KESIMPULAN}

Dari penjelasan yang telah diuraikan dalam penelitian ini maka dapat disimpulkan berbagai hal sebagai berikut:

1. Perancangan aplikasi pendataan ini menggunakan Rapid Application Development (RAD). Alat bantu perancangan yang digunakan pada aplikasi ini adalah FoD, CD, DFD, ERD, HIPO. Teknologi yang diterapkan adalah Laravel, Vue.js, Quasar, Cordova, dan MySQL.

2. Aplikasi sistem informasi pendataan relawan saksi ini dapat diakses melalui desktop browser, mobile browser, dan aplikasi Android.

3. Penggunaan aplikasi pendataan ini terbukti mampu mengurangi tingkat kerumitan, mengurangi pelaporan data yang sering overlap (tumpang tindih), dan mengurangi kecolongan data oleh pihak-pihak tidak bertanggung jawab.

4. Secara spesifik aplikasi ini telah meminimalisir fraud (kecolongan, penggelembungan, dan rekayasa data) oleh oknum-oknum tidak bertanggungjawab.

5. Aplikasi sudah dilengkapi fitur penginputan data master petugas, data master kordinator lapangan, data klasifikasi relawan, data klasifikasi penghubung, data klasifikasi saksi TPS, data klasifikasi saksi gugur, data klasifikasi temuan saksi TPS, dan data klasifikasi calon pemilih

6. Dengan aplikasi ini, kesulitan dan hambatan saat berkolaborasi di pilwali Samarinda 2020 menjadi berkurang misalkan pelaporan, dan sebagainya sesuai fitur yang ada.

7. Berbeda dengan mekanisme excel, aplikasi ini dapat diakses dengan mudah melalui browser dan android dimanapun berada selama tersedia koneksi internet.

Kemudian juga aplikasi pendataan relawan saksi ini bisa untuk membantu tim sukses melakukan sampling calon pemilih sebagai upaya pemetaan keberhasilan kampanya lapangan. 


\section{SARAN}

Adapun saran yang dapat disampaikan dari hasil penelitian ini adalah sebagai berikut:

1. Rancangan aplikasi ini dapat ditambahkan fitur untuk survey DPT dengan kriteriakriteria yang lebih variatif dan kompleks.

2. Kedepannya bisa diperluas lagi tidak hanya untuk skala pilwali, tapi bisa digunakan untuk pilkada, pilgub, atau bahkan pilpres.

3. Implementasi aplikasi ini perlu mekanisme yang lebih spesifik seperti kualifikasi tim lapangan, tim staf IT, tim pendata, atau bisa ditambahkan tim surveyor, dan human resource development (HRD) yang memastikan kinerja dan integritas tetap terjaga.

4. Bisa dibuatkan standart operational procedure (SOP) yang lebih spesifik agar mampu mengoptimalisasi fitur-fitur pada aplikasi ini, misalkan berapa jumlah tim ideal, syarat minimum, atau keahlian khusus.

5. Ada baiknya implementasi aplikasi ini dilakukan beberapa bulan sebelum memasuki masa kampanya agar ritme kerja tim tidak panik dan data yang dikumpulkan lebih berbobot.

Mengingat kegiatan pilwali, pilkada, dan pilpres dilakukan setiap 5 tahunan, artinya implementasi aplikasi ini juga bisa menjadi cara untuk pengarsipan dan pedoman merawat (maintenance) jaringan relawan saksi yang sudah susah payah dibangun.

\section{DAFTAR PUSTAKA}

[1] Aminudin, Cara Efektif Belajar Framework Laravel. Yogkarta: Lokomedia, 2015.

[2] Asnawati, U, Rekayasa Perangkat Lunak. Yogyakarta: Deepublish, 2015.

[3] Cholisin, Pengantar Ilmu Politik (Introduction to Political Science) (Alih bahasa oleh Zulkifly Hamid). Jakarta: PT Raja Grafindo, 2013.

[4] EMS, T, Web Programming for Beginners. Jakarta: PT Elex Media Komputindo, 2012.

[5] Irtanto, Dinamika Politik Lokal Era Otonomi Daerah. Yogyakarta: Pustaka Pelajar, 2013.
[6] Jones, M. B,. JSON Web Token (JWT). Internet Engineering Task Force: (IETF), 2015.

[7] Kendall, K. d, Analisis dan Perancangan Sistem, Edisi kelima - Jilid 1. Jakarta: PT. Indeks Kelompok Gramedia, 2015.

[8] Kristanto, A, Perancangan Sistem dan Aplikasinya. Yogyakarta: Gava Media, 2018.

[9] Lestari, P. L, Pengembangan Single Page Application Pada Sistem Informasi Akademik. Yogyakarta: ILKOM Jurnal Ilmiah, 2018.

[10] Muslihudin, M. O, Analisis dan Perancangan Sistem Informasi Menggunakan Model Terstruktur dan UML. Yogyakarta: Andi, 2016.

[11] Khalik N. P, M. R. (n.d.), "Pengaruh Komunikasi Tim Sukses Partai Politik Terhadap Hasil Pemenangan Pemilihan Kepala Daerah (Studi Tim Sukses Dpac PDIP Kecamatan Tombulu Kabupaten Minah asa)". Jurnal Ilmiah. Manado: Ilmu Komunikasi Fispol Unsrat, 2018.

[12] Putu, A, Sistem Informasi dan Implementasinya. Bandung: Informatika Bandung, 2014.

[13] Safaat, H. N, Pemrograman Aplikasi Mobile Smartphone danTablet PC Berbasis Android (edisi revisi). Bandung: Informatika, 2012.

[14] Samarinda.kompas, (2020). https://samarinda.kompas.com/read/2020 /07/21/22045981/pasangan-zairinsarwono-penuhi-syarat-calonindependen-pilkada-samarinda (diakses tanggal 14 November 2020, 10:00 Wita).

[15] Sugono, D, Kamus Besar Bahasa Indonesia Edisi Keempat. Jakarta: PT. Gramedia Pustaka Utama, 2008.

[16] Yanto, R,. Manajemen Basis Data Menggunakan MYSQL. Yogyakarta: Deepublish, 2016.

[17] UU Republik Indonesia Nomor 3 Tahun 1999 Tentang Pemilihan Umum. (1999). Jakarta. 